\title{
Low Power Passive Photovoltaic System Development to Assist Inconvenient Grid Connection Locations
}

\author{
Ranjit Singh Sarban Singh $^{1 *}$, Siva Kumar Subramaniam ${ }^{1}$, Siti Aisyah Anas ${ }^{1}$, Tan Chee Fai ${ }^{2}$ \\ ${ }^{1}$ Department of Computer Engineering, Faculty of Electronics and Computer Engineering, Melaka, Malaysia \\ ${ }^{2}$ Department of Design \& Innovation, Faculty of Mechanical Engineering, Universiti Teknikal Malaysia Melaka, \\ Hang Tuah Jaya, Melaka, Malaysia \\ Email: *ranjit.singh@utem.edu.my
}

Received November 1, 2012; revised January 5, 2013; accepted January 13, 2013

Copyright (C) 2013 Ranjit Singh Sarban Singh et al. This is an open access article distributed under the Creative Commons Attribution License, which permits unrestricted use, distribution, and reproduction in any medium, provided the original work is properly cited.

\begin{abstract}
Sun radiation is known as one of the cleanest energy available and free maintenance on the earth to support the extensive demand for electrical power requirement for large and small scale. This energy is known as most promising renewable energy available during the whole year. This fact has shown a very strong interest among the researchers, industries and consumers to develop technology and system that can harvest solar energy to electrical energy. A lot of researches have been done to explore the capability of sun as natural energy source which is capable to provide huge alternative support to the increasing demand of electrical power in society. All the research findings have been adaptively combined to design, develop and structure as a reliable finished product for end users implementation. The fast improving research in photovoltaic application has proven that photovoltaic renewable energy is considered as one of the most promising source to support the increasing demand in electrical utilization. Advantages implementing the photovoltaic technology will benefit during the fuel price increment and be insufficient of the non-renewable energy to support the increasing demand from the society. Looking into this factor, many industries have developed the electrical photovoltaic system in large, medium and small scale for implementation. Electricity is becoming an essential requirement because of the increasing demand for electrical power from the society. Due to the increasing demand for electrical power, many researches are conducted to support the conventional way of generating electricity. This research has explored many other available abundant renewable energy resources such as solar, wind and thermal which are largely available to support the increasing demand. In this research, researchers discovered that the solar energy is the main contributor to support the increasing demand for electricity. The research outcome has helped the industries to develop solar power photovoltaic systems. This paper discusses the approaches to design and develop a real-time $500 \mathrm{Watt}$ DC to AC Solar Power System. The system capability to store the harvested energy is discussed in this paper.
\end{abstract}

Keywords: 500 Watt; Power System; DC to AC System

\section{Introduction}

The application of photovoltaic (PV) systems is well introduced for stand-alone application, but in recent years there has been growing interest in stand-alone photovoltaic systems using DC to AC inverter. Stand-alone system consists of the photovoltaic (PV) module, storage battery, charge controller and inverter. PV modules are exposed to the sunlight to capture the solar radiation to generate the direct current (DC) electricity. Storage system is used to capture all the converted solar radiation into usable energy before converting the energy into

${ }^{*}$ Corresponding author. alternating current (AC) electricity. AC electricity energy is fed into the AC buildings distribution boards to provide sufficient energy supply without affecting the quality of power supply.

Solar PV system can be categorized into two end-user technology based on application of the technology. There are two types of solar PV system, mainly known as grid-tied (grid-connected) and stand-alone (off-grid) so lar PV systems. Grid-tied solar PV system is mainly connected to the national main power grid distribution system. This type of solar PV systems is usually installed or mounted on the building roof and sometimes integrated into the building. The integration of photovoltaic 
system into building can be called as Building Integrated Photovoltaics (BIPV) [1]. BIPV systems are configuration of a grid-connected solar PV system as shown in Figure 1.

Stand-alone solar PV system is usually the use of PV power source as primary power source, and the need of battery as storage to store the primary power source as electrical energy. Battery storage device is used as a centralized power supply source via an independent grid connected electrical network. Most of this kind of systems are installed or implement where cabling access to lay the electrical wiring is difficult. These systems are mostly economical Pierre-Auger project in Argentina [2] installed approximately 1500 stand-alone solar PV systems, each system will be analyzed in terms of invariant power consumption of 10 watt (W), environment excessive such as cloudy condition and operation principle for charging and discharging process. Design and economic [3] study is also important for proper stand-alone solar PV system design and development.

This paper presents a study on the development and performance analysis of a low power stand-alone solar PV system as a passive electric energy system to support the electrification for places where grid connection is difficult. The Universiti Teknikal Malaysia Melaka (UTeM) is selected as testing location, as UTeM is located at the equatorial region [4]. The development of this project focuses on applying a renewable-energy-based low power PV system to reduce the energy utilization at situation of low power consumption, and promotes the application of an environmentally-friendly and freely available energy resource.

\section{Related Research}

Passive or stand-alone solar PV system study has begun during the 90's. During the 90's stand-alone solar PV system was proposed to power the street lighting [5], solution to reduce and save the grid connected operating cost for electricity throughout the year. Once of the earliest stand-alone solar PV lighting system was implemented in New Mexico, USA. The Parks and Recreation Department of the City of Albuquerque installed 21 solar PV lighting systems around the area [6]. The

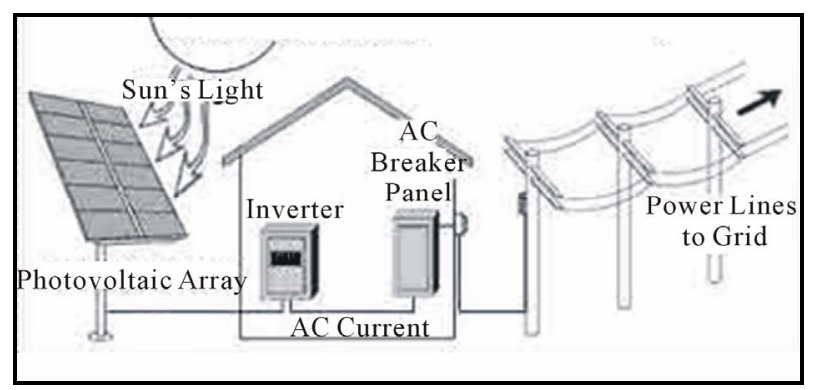

Figure 1. Grid-connected solar PV system. system was designed to power the lighting operation for6 hours with total load of 19.6 amp-hours (Ah) [6]. In 2003 University Thinghua, China implemented stand-alone photovoltaic lighting system with maximum power point tracking system (MPPT) [7]. This system is developed to provide a possible high efficiency solution to the high pressure sodium lighting system with special designed ballast and ignitor [7]. While the MPPT system is implemented to provide the highest possible power to the designed lighting system under various insolation and temperature [7].

\section{Basic Design and Operation of Low Power Photovoltaic System}

In the design and operation of solar PV system, capturing solar radiation as much as possible to store as usable energy is an important aspect. Voltage and current are the factors that should be met as operation requirement during the system functional period. To understand the basic operation of a solar PV system, analysis of the voltage generation from the PV module and PV inverter must be done, which will be discuss in the later section. The PV module is used to convert the sun radiation energy into DC electrical form of voltage and current. The PV inverter is a device to convert the $\mathrm{DC}$ to $\mathrm{AC}$ power which can be used by consumer or AC electrical devices.

Figure 2 shows the diagram of the proposed low power solar PV system. Low power solar PV system intends to operate independently off the conventional electric system. PV module produce continuous DC electrical energy during the daylight hours, hence, batteries are necessary to store the continuous DC electric energy from the PV module. In this process, charge controller device is necessary to avoid the voltage variation during the energy storing process. Furthermore, charge controller will prevent the battery over-charging and damage the PV module. There are two combinations for the low power solar PV system, DC system and AC system. For DC system, the DC electric energy that is stored into the battery storage is utilized directly without any complication and all the DC appliances are directly connected to the battery storage. AC system uses the PV inverter to convert the DC electrical energy from the battery storage to $\mathrm{AC}$ power for $\mathrm{AC}$ appliances.

\section{Photovoltaic System Development Research}

The building of the low power solar PV system for domestic use requires a short research on the geographical location, solar irradiation, and load requirements. In this paper, procedures were employed before the process of designing, selecting and calculating the rating of 


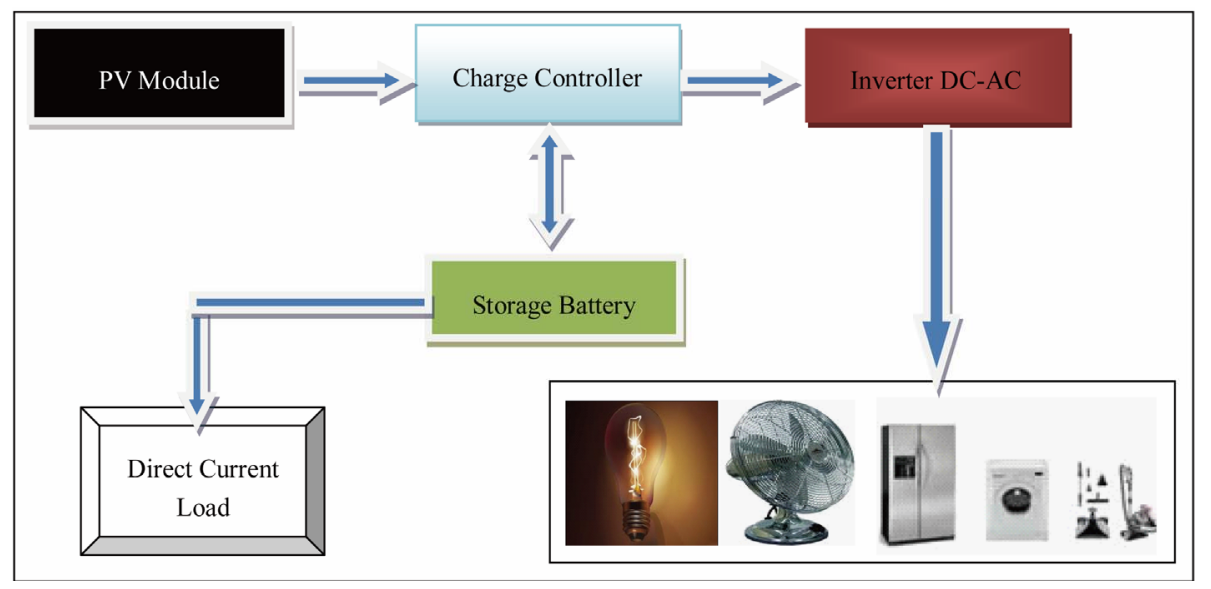

Figure 2. Schematic diagram of a low power solar PV system.

the equipment that employed in the low power solar PV system. Exploiting the solar radiation for system application is necessary before selecting and calculating the equipment rating for system development.

\subsection{Solar Radiation Measurement}

To perform the developed low power solar PV system, metrological and environmental data is necessary. Figure 3 shows the average Melaka solar radiation that reaches the ground every day for each month, and number of hours usability of sun radiation is compared with the system operation period. Melaka is among the states in Malaysia that receive an average of 4500 watt hours of sun radiation per day. In order to constantly receive 4500 watt hours of sun radiation, sky clearness is an important aspect to receive impressive sun radiation throughout the year. Figure 4 demonstrates the monthly sky clearness index, sky clearness result explains the strong availability of sun radiation. The clearness index measured at Melaka State approximately shows 0.495 . Based on this value, Melaka State is receiving $50 \%$ of the sun radiation that travelled to the earth. If the clearness index is at 1 or approximately at 1 , Melaka State will manage to receive extra $30 \%$ of sun radiation additional compare with the current sun radiation harvested. Besides that, weather plays an important role when measuring the system performance. Cloudy weather will reduce the sun radiation harvesting process and decreases the storage charging capacity.

\subsection{Estimating Load Description, PV Sizing, Battery Sizing}

Presented Table 1 is to estimate the total load and size of solar PV system. This estimation is adapted based on a basic requirement which supports the developed system power requirements. Firstly, load specification is derived to determine the total load requirement, then the size

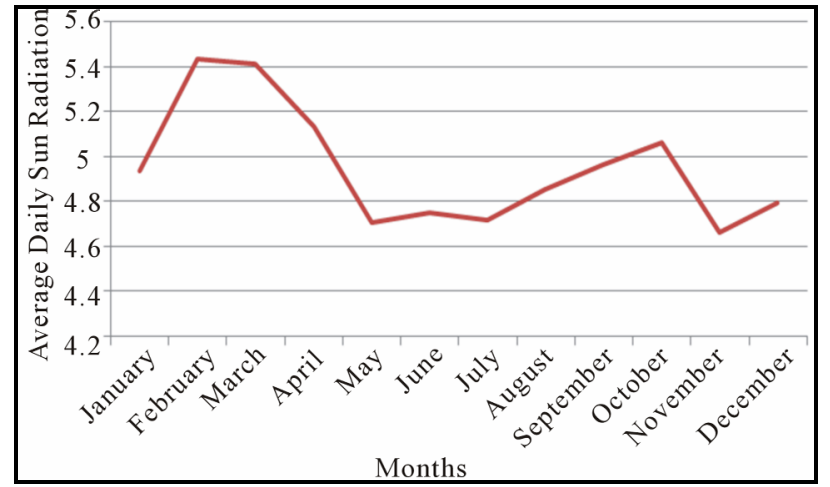

Figure 3. Melaka monthly sun radiation.

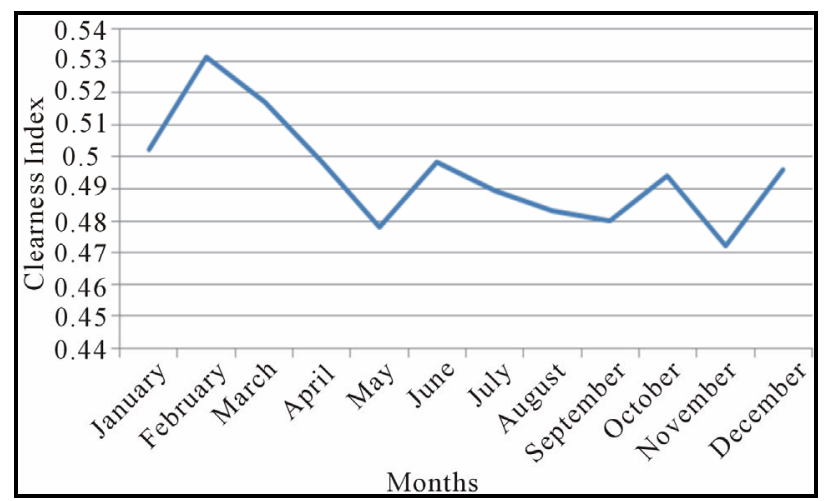

Figure 4. Monthly sky clearness index.

solar PV system array and the number of battery bank needed to store the energy. In this proposed system, bottom-up approach is adapted to design and developed the required solar PV system

\section{Construction of Low Power Solar Photovoltaic}

Construction of the low power solar PV system combines the PV module, charge controller, battery and inverter. For the safety precaution, the charge controller, battery 
Table 1. Load description for low power photovoltaic system.

\begin{tabular}{|c|c|c|c|}
\hline Appliance & Watt (W & Quantity Hours of usage & $\begin{array}{c}\text { Total energy/day } \\
(\mathrm{kWh} / \text { day })\end{array}$ \\
\hline $\begin{array}{l}\text { Electronics } \\
\text { lamps }\end{array}$ & 15 & 12 & $\begin{array}{c}15 \times 2 \times 12=0.36 \\
\mathrm{kWh} / \text { day }\end{array}$ \\
\hline Mobile charger & 10 & 1 & $\begin{array}{c}10 \times 1 \times 5=0.05 \\
\mathrm{kWh} / \text { day }\end{array}$ \\
\hline \multicolumn{3}{|c|}{ Total load } & $0.410 \mathrm{kWh} / \mathrm{Day}$ \\
\hline \multicolumn{3}{|c|}{ Battery Bus Voltage } & $12 \mathrm{~V}$ \\
\hline \multicolumn{3}{|c|}{$\begin{array}{c}\text { Total amp-hours a day }=\underline{410 \mathrm{Wh}} \\
12 \mathrm{~V}\end{array}$} & $35 \mathrm{Ah}$ \\
\hline \multicolumn{3}{|c|}{ Maximum DC power requirement } & 55 Watts \\
\hline $\begin{array}{r}\text { Allow } \\
\text { Required batt }\end{array}$ & \multicolumn{2}{|c|}{$\begin{array}{l}\text { Allowable depth of discharge } \\
\text { Required battery capacity }=(35 \mathrm{Ah} \times 7 \text { days })\end{array}$} & $\begin{array}{c}7 \text { days } \\
0.8 \\
245 \mathrm{Ah} \sim 250 \mathrm{Ah}\end{array}$ \\
\hline \multicolumn{3}{|c|}{$\begin{array}{c}\text { Selected battery rating } \\
\text { No. of batteries in parallel }=\underline{250 \mathrm{Ah}}= \\
250 \mathrm{Ah}\end{array}$} & $\begin{array}{c}300 \mathrm{Ah} \\
1\end{array}$ \\
\hline \multicolumn{3}{|c|}{ No. of batteries in series $=12 \mathrm{~V} / 12 \mathrm{~V}$} & 1 battery \\
\hline \multicolumn{3}{|c|}{$\begin{array}{l}\text { Battery round trip efficiency } \\
\text { Required array output per day }=410 \mathrm{Wh}= \\
0.85\end{array}$} & $\begin{array}{c}410 \mathrm{Wh} \\
0.85 \\
483 \mathrm{Wh}\end{array}$ \\
\hline \multicolumn{4}{|c|}{ PV sizing: } \\
\hline \multicolumn{3}{|c|}{ Selected PV module voltage } & $12 \mathrm{~V}$ \\
\hline \multicolumn{3}{|c|}{ Selected PV module power output } & $95 \mathrm{~W}$ \\
\hline \multicolumn{3}{|c|}{ Peak sun hours } & 4.5 hours \\
\hline \multicolumn{3}{|c|}{$\begin{array}{c}\text { Energy output per module per day }=95 \mathrm{~W} \times 4.5 \\
\text { hours }\end{array}$} & $427.5 \mathrm{Wh}$ \\
\hline \multicolumn{3}{|c|}{$\begin{array}{l}\text { Module energy output at operating temperature } \\
\qquad=0.85 \times 427.5 \mathrm{~W}\end{array}$} & $363.4 \mathrm{Wh}$ \\
\hline \multicolumn{3}{|c|}{$\begin{array}{c}\text { No. of modules required }=\underline{483 \mathrm{Wh}} \\
363.4 \mathrm{Wh}\end{array}$} & $1.3 \approx 2$ \\
\hline
\end{tabular}

and inverter is placed into a casing. Apart of that, the casing needs to ultimately protect all the main components from the water damage and heat damage. Since the designed system is mobile, practically the system can be move to a position with large solar radiation to harvest the optimum solar radiation capacity.

Figure 5 describes the overall low power solar PV system construction for low power application as describe in Table 1. Also, the low power photovoltaic system is protected with two switches, one (green) to switch on the battery power before letting the DC to AC conversion and second (red) to switch on the output alternating current for AC appliances which is connected to the wall socket.

\section{Low Power Photovoltaic System Analysis}

This section discusses the low power solar PV system analysis during the sunny day. Series 1 and series 2 in Figure 6 represent the temperature and voltage of the low power solar PV system. Observation results present a steady voltage increment to peak voltage at $1.00 \mathrm{pm}$.

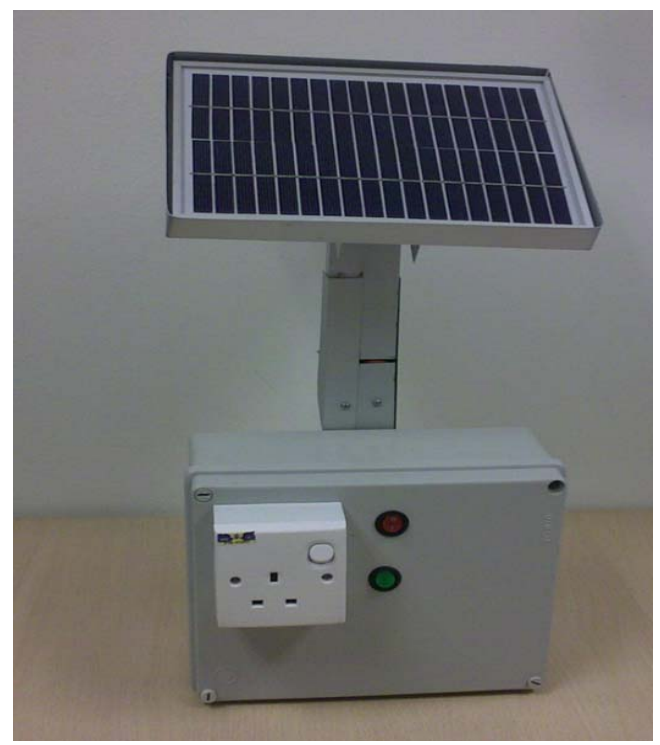

Figure 5. Low Power Solar PV system for low power home electrical appliances.

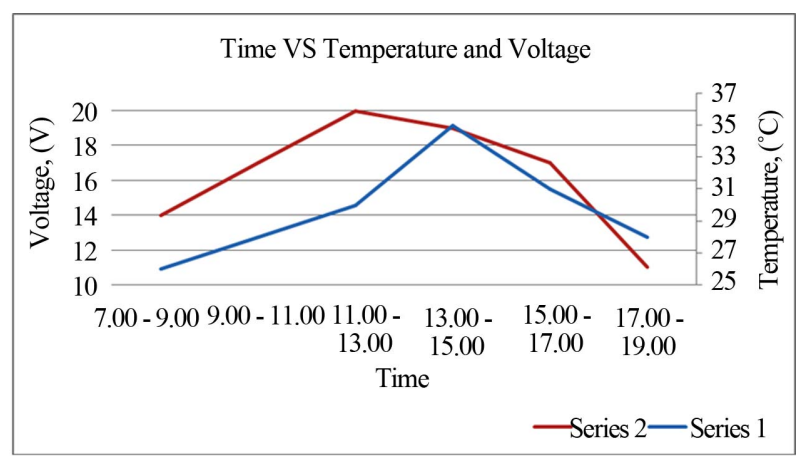

Figure 6. Time vs Temperature and Voltage Low Power Solar PV System.

Shortly after that, the temperature starts to increase and the voltage starts to decrease gradually during the sunset period. The cause of the voltage drop is because the increment in the system operation temperate. This causes the output voltage is absorbed as heat and reducing the system performances. The voltage shows an average of $1.5 \mathrm{~V} /{ }^{\circ} \mathrm{C}$ increment during the low power solar PV system charging process.

\subsection{Low Power Solar PV System Development Cost}

Installation costing for a photovoltaic system has always concern the users. To compare the total installation cost and the return of investment cost is necessary to convince the users. Table 2 shows the equipment and installation cost for low power solar PV system development. Total cost to install a low power solar PV system with 0.410 kWh power generation cost approximately MYR 1976.00 (Malaysia Ringgit). 
Table 2. Low Power Solar PV System Installation Cost.

\begin{tabular}{cccc}
\hline No. & Item & Life Span & Price \\
\hline 1. & Electronics Lamps $\times 3$ & 2 year & MYR 96.00 \\
2. & $\begin{array}{c}\text { Self Developed DC to } \\
\text { AC 500 Watt Inverter }\end{array}$ & 3 years & MYR 80.00 \\
3. & 12 Volt, 23 Watt Solar Panel & 20 years & MYR 560.00 \\
4. & 12 Volt, 7Ah Battery & 5 years & MYR 70.00 \\
5. & 12 Volt, 10 Ampere & 5 years & MYR 150.00 \\
6. & Maintenances Cost - Half a Year & & MYR 120.00 \\
7. & Installation Cost & & MYR 900.00 \\
& Total & & MYR 1976.00 \\
\hline
\end{tabular}

\subsection{Investment Return Cost}

The utilization of the low power solar PV system to support the inconvenient grid connection can reduce the grid economic costing. The economics return for the low power photovoltaic system is depended on the applicability towards the system. The investment return cost is the duration required to pay back the system investment cost.

According to the electricity tariff, cost of grid-connected load per kilowatts is MYR 0.218. From Table 1, total of MYR 33.00 annual salvage is saved with the system built for powering the load described in Table 1.

\section{Discussion}

An original low power solar PV system is developed to assist the inconveniency grid connection. Apart from that, indirectly this system can reduce the grid electricity energy consumption when the load in Table $\mathbf{1}$ is consumed via this system. Besides that, the implementation of the low power solar PV system reduces the carbon dioxide $\left(\mathrm{CO}_{2}\right)$ gas emission and also reduces the global warming.

\section{Conclusion}

The development of low power solar PV system is to assist the inconveniency of grid connection in the rural area. Also, low power solar PV system reduces $5 \%$ of the monthly electricity billing cost when applying the system to the following equipment mentioned in Table 1.

\section{Acknowledgements}

The authors would like to thank the Universiti Teknikal Malaysia Melaka (UTeM) for financial support of this research. This paper is supported under Universiti Teknikal Malaysia Melaka (UTeM) short term grant funding.

\section{REFERENCES}

[1] A. Collinson and J. Thornycroft, "Low Voltage Grid Connection of Photovoltaic Power Systems," ETSU Report, 1999.

[2] M. Gloeckler and J. Sites, "Evaluation of a 50-W StandAlone Photovoltaic System," Colorado State University Ft. Collins, Colorado, 2000.

[3] A. E.-S. A. Nafeh, "Design and Economic Analysis of a Stand-Alone PV System to Electrify a Remote Area Household in Egypt," The Open Renewable Energy Journal, Vol. 2, No. 2, 2009, pp. 33-37. doi:10.2174/1876387100902010033

[4] F. Zainuddin, N. Mohamad, S. Masri and M. N. A. Redzuan, "Feasibility Study of Electric Photovoltaic Solar Panel Set Application," Journal of Telecommunication, Electronic and Computer Engineering, Vol. 3 No. 1, 2010, pp. 21-30.

[5] J. David Bollinger, "Applications of Solar Energy to Power Stand-Alone Area and Street Lighting," Thesis, University of Missouri-Rolla, Rolla, 2007.

[6] S. R. Harrington and T. D. Hund, "Photovoltaic Lighting System Performance," Conference Record of the Twenty 5th IEEE Photovoltaic Specialists Conference, Washington DC, 13-17 May 1996, pp. 1307-1310.

[7] Z. Zhengming, L. Jianzheng and W. Jian, "Implementation of a Stand-Alone Photovoltaic Lighting System with Maximum Power Point Tracking and High Pressure Sodium Lamp," Proceedings of the 5th International Conference on Power Electronics and Drive Systems (PEDS), 17-20 November 2003, pp. 1570-1573. 